\title{
Determinants of uptake of post-partum intra-uterine contraceptive device among women delivering in a tertiary hospital, Odisha, India
}

\author{
Srabani Pradhan ${ }^{1}$, Jaya Singh Kshatri ${ }^{1 *}$, Rishika Sen ${ }^{3}$, \\ Arpika Aparajita Behera ${ }^{2}$, Radha Madhab Tripathy ${ }^{1}$
}

\author{
${ }^{1}$ Department of Community Medicine, ${ }^{2}$ Deapartment of Obstetrics and Gynecology, MKCG MCH, Berhampur, \\ Odisha, India \\ ${ }^{3}$ Department of Obstetrics and Gynecology, SCB MCH, Cuttack, Odisha, India
}

Received: 08 March 2017

Accepted: 07 April 2017

\section{*Correspondence:}

Dr. Jaya Singh Kshatri,

E-mail: smritijainagrawal@ rediffmail.com

Copyright: ( ) the author(s), publisher and licensee Medip Academy. This is an open-access article distributed under the terms of the Creative Commons Attribution Non-Commercial License, which permits unrestricted non-commercial use, distribution, and reproduction in any medium, provided the original work is properly cited.

\section{ABSTRACT}

Background: IUCDs are used by only two percent of the contraceptive users in India. There is a need for identifying the factors which influence the uptake of PPIUCD, so as to plan ways for increasing its usage. To determine the uptake and factors influencing the uptake of PPIUCD among the women delivering in a tertiary care hospital of Odisha

Methods: This was a case control study conducted at the Obstetrics Department of M.K.C.G Medical College, Berhampur. All those who had agreed for and had undergone PPIUCD insertion were included in cases and those who did not undergo PPIUCD insertion were pooled into controls.

Results: 94 cases and 188 controls were recruited. Significantly higher proportions of cases belonged to nuclear families, had one or more male child, did not want any future pregnancies, had heard about it prior to pregnancy and also had received counselling for the same during the antenatal period. The adjusted odds of uptake of PPIUCD in women having at least one male child is 10 (4.3-22.6) times that of mothers with no male children. The most common reasons told by controls for not taking up PPIUCD was disapproval from family members (42.6\%), followed by fear of complication (33\%) and preference for other methods of contraception $(20.2 \%)$.

Conclusions: In present study, we found that counselling in the antenatal period was a key point in increasing acceptance of post-partum IUCD. Desire for male child also influenced uptake of postpartum IUCD.

Keywords: Case-control, Determinants, PPIUCD, Uptake

\section{INTRODUCTION}

India having $2.4 \%$ of the world landmass harbours $17.5 \%$ of the world population. ${ }^{1}$ The annual growth rate of India in 2001-2011 was $1.2 \% .^{2}$ It is projected that we will surpass China to become the most populous country of the world by $2020 .{ }^{1}$ According to SRS 2012 our Total Fertility Rate (TFR) is 2.4, higher than the target of 2.1 set by National Population Policy $2000 .{ }^{3}$ We have a high unmet need for contraception of $20.5 \% .{ }^{4} 61 \%$ of births in India occur at intervals that are shorter than the recommended birth-to-birth interval of approximately 36 months. ${ }^{3}$

Less than half of the deliveries $(40 \%)$ in our country are institutional deliveries. ${ }^{5}$ This has been on the rise in recent years. In order to make best use of the opportunity provided by increased institutional deliveries and high motivation of the mother in the post-partum period for a reliable birth spacing or limiting method, adequate counselling should be done to ensure use of one or the other contraceptive method. ${ }^{6}$ Unlike hormonal contraceptive which influences breast feeding ,Intra 
uterine contraceptive device (IUCD) have no effect on breast feeding proving them to be a safe, reliable, inexpensive and long acting option to be used in the postpartum period. ${ }^{7}$

Despite all these strong points IUCDs are used by only two percent of the contraceptive users in India. ${ }^{5}$ Total post-partum IUCD (PPIUCD) insertions for the year 2013-14 was only $3,24,974$. $^{6}$

According to AHS 2011-12 TFR of Odisha was 2.3 with only $46.8 \%$ of the women were using any modern method for spacing of pregnancies. Only $0.4 \%$ of women in Odisha were using IUCD. ${ }^{8}$ HMIS report 2015-16 showed that total $1,94,884$ IUD insertions were ed conducted in Odisha out of which only 63078 post-partum. ${ }^{9}$

Reasons like educational status, future desire for children, preference for another contraceptive method, and fear of complications have been found to influences the uptake of PPIUCD. This suggests the need for identifying the factors which influence the uptake of PPIUCD, so as to plan ways for increasing its usage.

Hence, the present study aims at determining the uptake and factors influencing the uptake of PPIUCD among the women delivering in a tertiary care hospital of Odisha.

\section{METHODS}

This was a case control study conducted at the Obstetrics Department of M.K.C.G Medical College, Berhampur. The study duration was 3 months between September to November 2016. The study population were women aged 18 and above, who had delivered a live child and consented to be included in the study. Women less than 18 yrs of age, who had delivered a still born, intra uterine death (IUD) and/or had an abortion, who had a history of use of IUCD, who had uncontrolled PPH, chorioamnionitis, premature rupture of membranes (PROM) more than 18 hours, preterm premature rupture of membranes (PPROM) more than 18 hours and those who refused to give consent were excluded from the study. Among the study population, during the study period, all those who had agreed for and had undergone PPIUCD insertion were included in cases and those who did not undergo PPIUCD insertion were pooled into controls. Two controls were recruited by simple random sampling after each case. This resulted in a sample size of 282, i.e 94 cases 188 controls over a period of 3 months.

IEC clearance was obtained prior to the start of the study. Data was collected using a pre-designed pre-tested questionnaire administered by the investigators.

Analysis of data was done at the department of Community Medicine, MKCG Medical College using SPSS ver. 21.0. Chi-squared test was used to determine difference in proportions and logistic regression analysis was performed for the predictors. All tests were done at a significance level of 0.05 .

\section{RESULTS}

Total 282 mothers delivering in M.K.C.G Medical College from September to November 2016 fulfilling the inclusion criteria were taken into the study. Out of these 282 participants 94 were cases i.e who had PPIUCD inserted and 188 were controls i.e they had not inserted PPIUCD.

The mean age of cases was $27.8 \pm 2.39$ and significantly older than that of control 25.36 $\pm 3.07(\mathrm{t}=6.81, \mathrm{p}<0.001)$. Similarly, the age at marriage was significantly higher for cases than the controls (mean age at marriage cases = $20.4 \pm 1.71$, mean age at marriage controls $=19.5 \pm 1.66, \mathrm{t}$ $=3.970, \mathrm{p}<0.001)$.

Table 1 shows the socio-demographic profile of cases and controls. Most of the study participants both cases and controls had completed some level of schooling. Majority of study participants in both the groups were from nuclear family. However, higher proportion of controls came from a 3-generation family $(28.3 \%)$ as compared to cases $(13.8 \%)$. Around $81 \%$ of both PPIUCD users and non-users were from rural areas.

Table 1: Socio demographic profile of cases and control.

\begin{tabular}{|lll|}
\hline Education & & \\
\hline illiterate & $26(27.7 \%)$ & $73(39 \%)$ \\
\hline primary & $42(44.7 \%)$ & $63(33.7 \%)$ \\
\hline secondary & $18(9.1 \%)$ & $40(21.4 \%)$ \\
\hline higher & $8(8.5 \%)$ & $12(5.9 \%)$ \\
\hline SES & & \\
\hline upper & $5(5.3 \%)$ & $12(6.4 \%)$ \\
\hline Upper middle & $8(8.5 \%)$ & $41(21.9 \%)$ \\
\hline middle & $29(30.9 \%)$ & $60(32.1 \%)$ \\
\hline Lower middle & $31(33 \%)$ & $15(7.5 \%)$ \\
\hline Lower & $21(22.3 \%)$ & $60(32.1 \%)$ \\
\hline Type of family & & \\
\hline nuclear & $66(70.2 \%)$ & $110(58.8 \%)$ \\
\hline joint & $15(16 \%)$ & $25(12.8 \%)$ \\
\hline 3 generation & $13(13.8 \%)$ & $53(28.4 \%)$ \\
\hline Caste & & \\
\hline Gen/OBC & $71(75.5 \%)$ & $139(74.3 \%)$ \\
\hline SC & $19(20.2 \%)$ & $33(17.1 \%)$ \\
\hline ST & $4(4.3 \%)$ & $16(8.6 \%)$ \\
\hline Residence & & \\
\hline Rural & $76(80.9 \%)$ & $153(81.8 \%)$ \\
\hline urban & $18(19.1 \%)$ & $35(18.2 \%)$ \\
\hline
\end{tabular}

In univariated analysis, significantly higher proportions of cases belonged to nuclear families as compared to controls $\left(\chi^{2}=7.34, p=0.02\right)$. Following the same trend, significantly higher proportions of takers of PPIUCD had 
one or more male child $\left(\chi^{2}=55.4, \mathrm{p}<0.001\right)$, did not wanted any future pregnancies $\left(\chi^{2}=41.63, \mathrm{p}<0.001\right)$ as compared to those who did not inserted PPIUCD. Significantly higher mothers who underwent PPIUCD insertion had heard about it prior to pregnancy $\left(\chi^{2}=11.5\right.$, $\mathrm{p}=0.001$ ) and also had received counselling for the same during the antenatal period $\left(\chi^{2}=4.57, p=0.03\right)$.
In multivariated analysis, the adjusted odds of uptake of PPIUCD in women having at least one male child is 10 (4.3-22.6) times that of mothers with no male children. Women who had no further desire of pregnancy where 6 times (2.8-12.9) more likely to take PPIUCD than those with desire of future pregnancies.

Table 2: Univariate and multivariate analysis for the factors influencing uptake of PPIUCD.

\begin{tabular}{|c|c|c|c|c|c|c|}
\hline \multirow{2}{*}{ Variable } & & \multicolumn{3}{|c|}{ Univariate Analysis } & \multicolumn{2}{|c|}{ Logistic regression } \\
\hline & & $\begin{array}{l}\text { Cases n, } \\
(\%)\end{array}$ & Controls n, (\%) & $\begin{array}{l}\text { Chi Sq } \\
\text { (P-value) }\end{array}$ & $\begin{array}{l}\text { Adjusted OR } \\
(95 \% \mathrm{CI})\end{array}$ & p-value \\
\hline \multirow{4}{*}{ Education } & Illiterate & $26(27.7 \%)$ & $73(39 \%)$ & \multirow{4}{*}{$\begin{array}{l}\chi^{2}=5.11 \\
P=.164\end{array}$} & 1 (Ref.) & - \\
\hline & Primary & $42(44.7 \%)$ & $63(33.7 \%)$ & & $0.71(0.26-1.9)$ & 0.50 \\
\hline & Secondary & $18(9.1 \%)$ & $40(21.4 \%)$ & & $1.5(0.53-4.2)$ & 0.44 \\
\hline & Higher & $8(8.5 \%)$ & $12(5.9 \%)$ & & $2.23(0.43-11.5)$ & 0.34 \\
\hline \multirow{5}{*}{ SES } & Lower & $21-22.3 \%$ & $60-32.1 \%$ & \multirow{5}{*}{$\begin{array}{l}\chi^{2}=34.05 \\
P<0.001\end{array}$} & 1 (Ref.) & - \\
\hline & Upper Lower & $31-33 \%$ & $15-7.5 \%$ & & $3.3(0.52-20.9)$ & 0.20 \\
\hline & Lower Middle & $29-30.9 \%$ & $60-32.1 \%$ & & $1.6(0.33-8.1)$ & 0.55 \\
\hline & Upper Middle & $8-8.5 \%$ & $41-21.9 \%$ & & $0.8(0.15-4.6)$ & 0.83 \\
\hline & Upper & $5(5.3 \%)$ & $12(6.4 \%)$ & & $2.3(0.40-13.4)$ & 0.35 \\
\hline \multirow{3}{*}{ Family Type } & 3-Gen & $13(13.8 \%)$ & $53(28.3 \%)$ & \multirow{3}{*}{$\begin{array}{l}\chi^{2}=7.344 \\
P=0.025\end{array}$} & 1 (Ref.) & - \\
\hline & Joint & $15(16 \%)$ & $25(12.8 \%)$ & & $0.37(0.12-1.07)$ & 0.07 \\
\hline & Nuclear & $66(70.2 \%)$ & $110(58.8 \%)$ & & $1.2(0.5-3.1)$ & 0.65 \\
\hline \multirow{2}{*}{ residence } & rural & $76(80.9 \%)$ & $153(81.8 \%)$ & \multirow{2}{*}{$\begin{array}{l}\chi^{2}=0.039 \\
p=.844\end{array}$} & $1(\mathrm{ref})$ & - \\
\hline & urban & $18(19.1 \%)$ & $35(18.2 \%)$ & & $0.89(.32-2.44)$ & .825 \\
\hline \multirow{2}{*}{ Male Children } & No & $30-31.9 \%$ & $145-77.5 \%$ & \multirow{2}{*}{$\begin{array}{l}\chi^{2}=55.43 \\
P<0.001\end{array}$} & 1 (Ref.) & - \\
\hline & Yes & $64-68.1 \%$ & $43-22.5 \%$ & & $9.9(4.3-22.6)$ & $<0.01$ \\
\hline \multirow{2}{*}{$\begin{array}{l}\text { Desire for future } \\
\text { children }\end{array}$} & Yes & $23(24.5 \%)$ & $122(65.2 \%)$ & \multirow{2}{*}{$\begin{array}{l}\chi^{2}=41.63 \\
P<0.001\end{array}$} & 1(Ref.) & - \\
\hline & No & $71(75.5 \%)$ & $66(34.8 \%)$ & & $6.1(2.8-12.9)$ & $<0.01$ \\
\hline \multirow{2}{*}{$\begin{array}{l}\text { Awareness of } \\
\text { PPIUCD prior to } \\
\text { pregnancy }\end{array}$} & No & $20(21.3 \%)$ & $79(41.7 \%)$ & \multirow{2}{*}{$\begin{array}{l}\chi^{2}=11.501 \\
\mathrm{P}=0.001\end{array}$} & 1 (Ref.) & - \\
\hline & Yes & $74(78.7 \%)$ & $109(58.3 \%)$ & & $1.6(0.66-3.9)$ & 0.30 \\
\hline \multirow{2}{*}{$\begin{array}{l}\text { Counselling of } \\
\text { PPIUCD during } \\
\text { ANC }\end{array}$} & No & $67(71.3 \%)$ & $154(82.4 \%)$ & \multirow{2}{*}{$\begin{array}{l}\chi^{2}=4.57 \\
P=0.03\end{array}$} & 1(Ref.) & - \\
\hline & Yes & $27(28.7 \%)$ & $35(17.6 \%)$ & & $6.5(2.3-17.8)$ & $<0.01$ \\
\hline
\end{tabular}

Table 3: Reason for non-uptake of PPIUCD in controls.

\begin{tabular}{|lll|}
\hline Reason for refusal & N & $\%$ \\
\hline Disapproval of family members & 80 & 42.6 \\
\hline Fear of complication & 38 & 20.2 \\
\hline Preference to use other method & 41 & 22 \\
\hline Religious beliefs & 6 & 3.1 \\
\hline Interferes with sexual intercourse & 2 & 1.2 \\
\hline No reason & 21 & 11.5 \\
\hline
\end{tabular}

Pregnant women who have received counselling about PPIUCD in their ante natal period were 6.5 (2.3-17.8) times more likely to get IUCD inserted in their postpartum period. The most common reasons told by controls for not taking up PPIUCD was disapproval from family members (42.6\%), followed by fear of complication $(33 \%)$ and preference for other methods of contraception $(20.2 \%)$.

\section{DISCUSSION}

Majority of the cases in our study had primary or secondary level of schooling. Similar findings were seen in the study conducted by Agarwal et al. ${ }^{10}$ Most of the ppiucd user were of lower and middle income group. A study conducted by Sebastian et al had also similar findings. ${ }^{11}$

In our study counselling during the antenatal period was found to significantly increase the chances of uptake of IUCD in post-partum period. Similar results were also found in a study conducted in Uttar Pradesh India were $44 \%$ of the couples counselled underwent PPIUCD 
insertion. ${ }^{8}$ A prospective cohort study in India also found a significant increase $(61.8 \%$ versus $30.6 \%)$ in contraceptive use in postpartum by women in the intervention group compared with the control group. The intervention included an educational campaign carried out by community workers using leaflets, posters, wall paintings and booklets. ${ }^{11}$

Similar to this study in another study the commonest reason for declining PPIUCD insertion was family refusal $(53.6 \%)$ followed by preference for other methods $(13.6 \%)$ in women counselled in antenatal period..$^{10}$ However, Sanskriti $\mathrm{P}$ et al found that predominant son preference and the belief that PPIUCD insertion might hinder their chance for future conception was the second most common reason for refusal in multipara $(65 \%){ }^{12}$

\section{CONCLUSION}

In present study, we found that counselling in the antenatal period was a key point in increasing acceptance of post partum IUCD. Desire for male child also influenced uptake of postpartum IUCD. Women having desire for future pregnancies did not choose IUCD as the preferred method.

Thorough counselling during the antenatal period involving family members is very essential for promoting the uptake of PPIUCD. Women and her family members need to be counselled that intra uterine devices are highly effective, safe method of contraception which does not interfere with future pregnancies. Gender equality needs to be promoted so as to remove the difference between male and female child.

Funding: No funding sources

Conflict of interest: None declared

Ethical approval: The study was approved by the Institutional Ethics Committee

\section{REFERENCES}

1. India to surpass China by 2022 to become world's most populous nation | The Indian Express. Available from:

http://indianexpress.com/article/india/indiaothers/india-to-surpass-china-by-2022-to-becomeworlds-most-populous-nation/

2. Population growth (annual \%). Data. Available from: http://data.worldbank.org/indicator/SP.POP.GROW
3. Government of India M of HA. SRS 2012. Available from:

http://www.censusindia.gov.in/vital_statistics/SRS_ Reports_2012.html

4. Government of India. Ministry of health and family welfare. DLHS III,2007-08. Available from: http://rchiips.org/pdf/india_report_dlhs-3.pdf

5. Government of India. Ministry of health and family welfare. NFHS III, 2005-06. Available from: http://dhsprogram.com/pubs/pdf/FRIND3/FRIND3Vol 1andVol 2.pdf

6. Janshankya Sthirata Kosh. Annual Report 2013-14. Available from: http://www.jsk.gov.in/JSKAnnual\%20Report\%202013-14.pdf

7. Díaz S, Zepeda A, Maturana X, Reyes MV, Miranda $\mathrm{P}$, Casado ME, et al. Fertility regulation in nursing women: IX. Contraceptive performance, duration of lactation, infant growth, and bleeding patterns during use of progesterone vaginal rings, progestin-only pills, Norplant ${ }^{\circledR}$ implants, and Copper T 380-A intrauterine devices. Contracep. 1997;56(4):223-32.

8. Agarwal N, Gupta M, Sharma A, Arora R. Antenatal counselling as a tool to increase acceptability of postpartum intrauterine contraceptive device insertion in a tertiary care hospital. Int $\mathbf{J}$ Reprod Contracep Obstet Gynaecol. 2015;4(2):1137-41.

9. Sebastian MP et al. Increasing postpartum contraception in rural India: evaluation of a community-based behaviour change communication intervention. Int Perspectv Sex Reprod Health. 2012;38(2):68-77.

10. Sanskriti P, Amita T, Pratima M, Rupali D, Jyotsna $\mathrm{S}$, Anita K. Exploring reasons behind Low acceptance for PPIUCD in postnatal women. New Indian J Surg. 2011;2(4):246.

11. Vital Statistics Division Office of the Registrar General and Census Commissioner, India. AHS 20011-12 Fact Sheet Odisha.

12. National Health Mission Department of Health and Family Welfare Govt. of Odisha. Odisha health management information system brochure 2015-16.

Cite this article as: Pradhan S, Kshatri JS, Sen R, Behera AA, Tripathy RM. Determinants of uptake of post-partum intra-uterine contraceptive device among women delivering in a tertiary hospital, Odisha, India. Int J Reprod Contracept Obstet Gynecol 2017;6:2017-20. 